\title{
LA CONTRIBUCIÓN DE JOSÉ GAOS A LA HISTORIA DE LAS IDEAS EN HISPANOAMERICA
}

Es difícil precisar y delimitar la contribución de José Gaos a la historia de las ideas en los paises de habla española, ya que supo ponerse en el centro de un movimiento muy amplio, que contribuyó a expandir y potenciar de forma importante, y si se quiere decisiva, pero en el que no estaba solo ni muchísimo menos. Tratar de situar la figura de Gaos dentro de este movimiento, y precisar con exactitud el lugar y la importancia de sus aportaciones, es el principal intento de este escrito.

\section{Ortega y Gasset y su teoria de la "circunstancia"}

Sin lugar a dudas, el factor fundamental en la creación y difusión de este movimiento de historia de las ideas es el legado filosófico de Ortega y Gasset. En 1914 habla publicado este pensador su primer libro, Meditaciones del Quijote, con el que inicia la exposición de su "circunstancialismo". "Yo soy yo y mi circunstancia, y si no la salvo a ella no me salvo yo", habia escrito Ortega en dicho libro. Este supone una reacción violenta contra el neokantismo de que Ortega había sido imbuido en Alemania, en busca de una fila sofía que aclare el sentido y el destino de lo español. "Dios mío, ¿qué es España? -se pregunta-. En la anchura del orbe, en medio de las razas innumerables, perdida entre el ayer ilimitado y el mañana sin fin, bajo la frialdad inmensa y cósmica del parpadeo astral, equé es esta España, ésta como proa del alma continental? ¿Dónde está, decidme, una palabra clara, una sola palabra radiante que pueda satisfacer a un corazón honrado y a una mente delicada, una palabra que alumbre el destino de España?". 1 En busca de una respuesta a esta pregunta angustiada, Ortega hace pie en la vida individual, a la que califica de realidad primaria o realidad radical, como gusta decir; radical, en el sentido de que todas las demás se hallan en ella radicadas, siendo, en cuanto separadas, algo abstracto, esquemático, secundario y derivado respecto a la vida de cada cual. Pero, bien entendido, que esta vida individual no es "conciencia" como en el idealismo, ni "cultura", como en el neokantismo, sino que consiste en el diálogo entre el "yo y sus circunstancias". Toda "la vida social, como las demás formas de cultura, se nos dan

1 Meditaciones del Quijote, Madrid, 1956, pp. 76-77. 
bajo la especie de vida individual", asegura; ${ }^{2}$ y la labor de la filosofía debe consistir precisamente en "radicar esa famosa cultura -que pretende serlo libre de espacio y tiempo: utopismo y ucronismo-, aceptando la servidumbre de la gleba temporal, la adscripción a un lugar y una fecha que es la realidad radical, que es la vida efectiva, haciendo de ella un principio frente a los principios abstractos de la cultura". 3 Ahora bien: esta adscripción a espacio-tiempo es precisamente la búsqueda de la circunstancia, y en esto debe consistir el sentido de la vida para cada cual: la aceptación de nuestra circunstancia. Por eso puede decir Ortega que "la reabsorción de la circunstancia es el destino concreto del hombre". ${ }^{4} \mathrm{Y}$ en otro lugar: "cada cual existe náufrago en su circunstancia. En ella tiene, quiera o no, que bracear para sostenerse a flote". 5 Idea que implica la de salvación, como nos lo confirman sus propias palabras de que "el hombre no puede salvarse si, a la vez, no salva su contorno".

Es, por lo demás, obvio que la circunstancia, entendida orteguianamente como vida individual, supone al mismo tiempo una "perspectiva", y como tal tiene siempre un primer término, y tras éste, otros, hasta uno último. "Ahora bien -dice Ortega-, el primer término de mi circunstancia era y es España, como el último es... tal vez la Mesopotamia". crito en las Meditaciones del Quijote: "Mi salida natural hacia el universo se abre por los puertos del Guadarrama o el campo de Ontigola. Este sector de la realidad circunstante forma la otra mitad de mi persona: sólo a través de él puedo integrarme y ser plenamente yo mismo".7 Muchos años después volvería a confirmarlo: "Mi destino individual se me aparecía y sigue apareciéndoseme como inseparable del destino de mi pueblo." 8

Esta doctrina de la "circunstancia", si por un lado le lleva a Ortega a una nueva filosofía de lo español, por otro implica una preocupación por la historia de esa "circunstancia" y, sobre todo, de su evolución intelectual, es decir, lleva a la historia de las ideas.

Esta línea orteguiana de preocupación por las circunstancias y, en forma primaria, por la circunstancia nacional, tenía tradición en España, en cuya literatura ideológica el tema había adquirido carácter predominante, desde Quevedo y Gracián, hasta Larra, Costa, Ganivet y, muy especialmente, la generación del 98 , en la que Unamuno acababa de publicar Del sentimiento trágico de la vida (1919), último libro sobre el problema, puesto que de una interpretación de lo español se trataba. Cuando al año siguiente, aparecen

2 Ibid., p. 16.

3 Prólogo para alemanes, Madrid, 1958; p. 60.

4 Meditaciones del Quijote, p. 18.

5 Prólogo para alemanes, p. 62.

6 Ibid., p. 77.

7 Meditaciones del Quijote, p. 18.

8 Prólogo para alemanes, p. 82. 
las Meditaciones del Quijote ya no se trata sólo de un libro más sobre el mismo tema, sino de la justificación de una actitud intelectual que gozaba de larga tradición en nuestra patria.

\section{El "circunstancialismo" como promotor de la historia de las ideas}

Ahora bien, si en el primer aspecto de elaboración de una filosofía de lo español el libro de Ortega puede inscribirse en esa tradición de que hemos hablado, en el segundo aspecto, en cuanto ocupación y preocupación con la historia de las ideas de la circunstancia patria inaugura un movimiento de incalculables consecuencias y de fecundidad pasmosa. $Y$ especialmente en España, donde los pensadores progresistas han tenido por norma toda desvinculación con el pasado nacional para inspirar su afán renovador en fuentes extranjeras, como el tan cacareado programa de la "europeización"; así pudo escribir Menéndez Pidal todavía en 1947: "las izquierdas siempre se mostraron muy poco inclinadas a estudiar y afirmar en las tradiciones históricas aspectos coincidentes con la propia ideologia".9 La preocupación por la circunstancia humana, que es siempre histórica, lleva lógicamente a filosofar sobre esa historia, y dado que la circunstancia más próxima a la filosofía es su propia historia, ello supone una historia de las ideas tanto como de las circunstancias..$^{10}$ En esta inspiración tiene su origen el movimiento que surge en España durante la primera mitad del siglo, y en el que figuran como principales cultivadores José Gaos, Maria Zambrano, L. Recaséns Siches, J. D. García Bacca y Joaquín Xirau. De este último -cuyos libros sobre Vives, Lulio y Cossio son ya clásicos-, son las siguientes palabras: "Para acabar con la enojosa e inútil polémica sobre el valor de la Filosofía peninsular, ibamos a emprender en la Universidad de Barcelona - con un grupo de jóvenes y distinguidos colaboradores-, el estudio monográfico, minucioso y objetivo, de las más destacadas personalidades del pensamiento hispano, con el objeto de incorporarlo, con sencillez, en la justa medida en que ello fuera preciso, en la evolución general de las doctrinas filosóficas." 11

Si de España pasamos a América, nos encontramos con una serie de fenómenos paralelos. Una característica, en efecto, de la literatura hispanoamericana es la preocupación por lo autóctono y, en general, por sus diferentes circunstancias nacionales y su destino como pueblos. En esta línea habrá que inscribir obras como Ariel, de Rodó; Facundo, de Sarmiento; Insularismo, de Pedreira; La raza cósmica, de Vasconcelos; Radiografía de la Pampa, de

- R. Menéndez Pidal, Los españoles en la historia, Col. Austral, 1959, p. 218.

10 Con parecidas palabras viene a decirlo $\mathrm{J}$. Gaos en su libro Filosofia mexicana de nuestros dias, Impr. Universitaria, México, 1954, pp. 311-312.

¥1 Obras de Joaquin Xirau, México, 1963, p. 247. 
Martinez Estrada, y varias más. Lo mismo viene a ocurrir con la atención prestada a la historia de las ideas, de donde surgen libros como La evolución de las ideas argentinas, de Ingenieros; o la Historia de la filosofía en México, de Samuel Ramos.

La pregunta inmediata a la vista de tales hechos salta por sí sola: ¿Qué relación guarda Ortega y Gasset con todo esto? Es evidente que algunos, bastantes, de estos libros fueron publicados antes de que la doctrina orteguiana del "circunstancialismo" fuese conocida en América y en consecuencia no pudieron estar inspirados por ella. El valor de dicha doctrina, más que en servir de inspiración a tales productos intelectuales - como, en efecto, lo fue muchas veces- está en haber sabido captar una faceta muy profunda y rica en el alma de los pueblos de habla española. La teoría orteguiana de la "circunstancia" es la justificación filosófica de ese quehacer intelectual, en muchos casos posterior, pero en otros tantos anterior a la enunciación de dicha teoría. Y ésa ha sido precisamente la gran genialidad de Ortega: la de haber sabido captar inconscientemente y justificar intelectualmente una actitud filosófica que es producto de la espontaneidad del hombre hispánico y de unas constantes literarias comunes tanto a españoles como a hispanoamericanos.

Esto no quiere decir, sin embargo, que en otros casos la doctrina orteguiana no haya servido de estímulo directo para la realización de una obra. El caso más patente y sintomático es el de Samuel Ramos, que se había movido precisamente en los dos planos anteriormente citados. Con su Perfil del hombre y la cultura en México (1934), Ramos pretende un psicoanálisis adleriano del mexicano, al estilo con que tantos autores habían pretendido en la Península hacer un análisis e interpretación del hombre español. Su obra Historia de la filosofía en México (1943), se mueve en el otro plano: el de la historia de las ideas, de las circunstancias nacionales, con lo que Samuel Ramos ha cumplido con la inspiración orteguiana, en las dos direcciones de su "circunstancialismo" de que hablábamos al principio. Y de aquí el enorme asombro que recién llegado a México experimenta José Gaos, con la lectura del Perfil del hombre y la cultura en México; asombro del que nos dejó primera constancia en una nota de lectura, ${ }^{12}$ pero sobre el que ha vuelto a insistir tantas veces como el tema ha salido al paso.

Esta inspiración orteguiana de Samuel Ramos era algo perfectamente consciente y querido por el pensador mexicano; por ello es interesante citar unas palabras suyas dónde expresa esta actitud, dado sobre todo lo que tienen de sintomático y de precursor de un movimiento que va a adquirir amplias dimensiones y repercusiones: "Una generación intelectual - dice- que comenzó a actuar públicamente entre 1925 y 1930 se sentía inconforme con

12 Letras de México, 15 de junio de 1939. Recogido en el volumen Pensamiento de lengua española, Ed. Stylo, México, 1945. 
el romanticismo filosófico de Caso y Vasconcelos. Después de una revisión crítica de sus doctrinas encontraba infundado el antiintelectualismo, pero tampoco quería volver al racionalismo clásico. En esta perplejidad, empiezan a llegar a México los libros de Ortega y Gasset, y en el primero de ellos, las Meditaciones del Quijote, encuentra la solución al conflicto en la doctrina de la razón vital. Por otra parte, a causa de la revolución, se habia operado un cambio espiritual que, iniciado por el año 1915, se había ido aclarando en las conciencias y podía definirse en estos términos: México había sido descubierto. Era un movimiento nacionalista que se extendia poco a poco en la cultura mexicana... la filosofía parecía no caber dentro de este cuadro ideal del nacionalismo, porque ella ha pretendido siempre colocarse en un punto de vista universal humano, rebelde a las determinaciones concretas del espacio y del tiempo, es decir, a la historia. Ortega y Gasset vino también a resolver el problema mostrando la historicidad de la filosofía en $E l$ tema de nuestro tiempo. Reuniendo estas ideas con algunas otras que había expuesto en las Meditaciones del Quijote, aquella generación mexicana encontraba la justificación epistemológica de una filosofía nacional." ${ }^{13}$

\section{Ortega y Gaos}

Hemos hablado ya de Gaos, y justo en el momento tenemos los antecedentes necesarios para explicitar sus importantes aportaciones y el lugar que ocupa en la constitución formal de la historia de las ideas en Hispanoamérica. Este lugar vemos que está en estrechísima relación con la función docente de Ortega, de quien Gaos fue discípulo preferido en España. Sobre este particular ha escrito en sus Confesiones profesionales: "Soy reconocido, y siempre me he reconocido yo mismo, por discípulo de Ortega y Gasset. Hasta me he tenido, y no sólo íntimamente, sino también más o menos públicamente, por su discípulo más fiel y predilecto, aunque desde hace algún tiempo no puedo menos de pensar que en tal puesto o condición me reemplazó Julián Marías, y que, aunque éste no me hubiera reemplazado, la divergencia de posición tomada en la guerra civil con todas sus consecuencias, haya hecho su efecto en el ánimo de Ortega, si no en el mío." 14

La influencia de Ortega sobre su discípulo fue importante, aunque no tanta que no puedan vislumbrarse algunas diferencias desde el primer momento, como ya insinúa Gaos en las palabras anteriores. En efecto, durante los años de la República, sin necesidad de llegar a la guerra civil, surge la primera discrepancia; cuando Ortega inscribe como partido político la Agrupación al Servicio de la República, fundada por él con Marañón y Pérez de

13 Historia de la filosofía en México, México, 1943. p. 149.

14 José Gaos, Confesiones profesionales, México, 1958, pp. 6o-61. 
Ayala, José Gaos, que no estaba de acuerdo, se afilió al partido socialista, en el que militó hasta su salida de España en 1938.

Pero las discrepancias no fueron sólo políticas, sino también filosóficas. La primera surgió ante la diferente interpretación de la filosofía del propio Ortega. En 1935, al celebrarse las bodas de plata del maestro con su cátedra, la Facultad de Filosof́a y Letras organizó -entre otros actos- unas conferencias de Gaos sobre la obra de Ortega, en la que aquél incluye a Ortega entre los grandes filósofos culturalistas, asistemáticos y antimetafísicos, lo que no le agradó. He aquí cómo lo cuenta el mismo Gaos: "Naturalmente, el maestro supo de la exposición del discípulo. Al saber de ella, torció el gesto, no le hizo gracia. Pero ante la insistencia tan firme como respetuosa del discípulo, se quedó pensativo y concluyó afectuoso. Había debido intuir que el discípulo intentaba la salvación de sí mismo intentando la salvación de la enorme circunstancia que era para él el maestro, por la única vía por la que divisaba salida, la de 'potenciar' lo natural del maestro frente a lo adventicio en él. Que no se salva a nadie tratando de hacer de él lo que no fue, aunque él mismo quisiera serlo. Sino tratando de hacer valer lo que realmente fuera, aun a pesar suyo." 15

Esta discrepancia aparentemente superficial, revela un distinto entendimiento de la filosofía y de su función, como se irá haciendo patente en la evolución del pensamiento de Gaos tras su arribada a México. El "circunstancialismo" y "perspectivismo" orteguiano van paulatinamente convirtiéndose en un individualismo y personalismo cada vez mayores, todo ello bajo un historicismo y raciovitalismo declarados, sin que quepa discernir con claridad lo que pertenece a Ortega y lo que es aportación personal de Gaos. tl mismo así lo reconoce en el siguiente párrafo, que ha reproducido en varias publicaciones: "Precisar en todos los puntos hasta dónde lo que pienso es una mera reproducción de esta filosofía - la de Ortega- o prolongación, reacción, ocurrencias mías, fuera interesante en una doble dirección inversa: reconocerle lo suyo y no achacarle lo que no querría aceptar. Pero tal puntualización me es imposible. Durante años, he vivido en convivencia frecuentemente diaria con él. He sido el oyente de palabras o el interlocutor de conversaciones en que se precisaban sus propias ideas en gestación, he leído originales inéditos. Así, ya no sé, si tal idea que pienso, si tal razonamiento que hago, si tal ejemplo o expresión de que me sirvo, lo he recibido de él, se me ocurrió al oírle o leerle a él, o se me ocurrió aparte y después de la convivencia con él. Alguna vez me ha sucedido comprobar que tal idea o expresión que consideraba como mía me la había apropiado de él, asimilándomela hasta el punto de olvidar su origen." 16

16 Sobre Ortega y Gasset y otros trabajos de historia de las ideas en España y la América española, Imp. Universitaria, México, 1957; p. 84 .

16 Dos ideas de la filosofia; párrafo reproducido en Sobre Ortega y Gasset..., pp. 99100. 
$Y$ lo que ocurre con Gaos, viene a ocurrir con nosotros, al pretender delimitar las fronteras de ambos pensamientos. Algo de ello creo que se aclara en el estudio que hace tiempo dediqué a la obra de Gaos, ${ }^{17}$ pero como éste no es el propósito del presente ensayo, allí remitiremos al lector interesado. De momento, y a nuestro exclusivo fin, sólo nos interesa destacar el papel que José Gaos ha desempeñado, no ya en la potenciación y exposición de la doctrina orteguiana, sino en lograr plena conciencia de su fecundidad en lo referente al estímulo y fundamentación de la historia de las ideas en los países de lengua española. Y éste sí que ha sido el extraordinario mérito de Gaos, por el que el discípulo se coloca a la altura del maestro: José Gaos representa, en este sentido, el momento en que la doctrina orteguiana adquiere conciencia, y es claro que sólo cuando una doctrina se hace consciente logra toda su capacidad creadora; por ello, al adquirir tal conciencia, Gaos impulsa y potencia en su nivel más alto la filosofía de Ortega. Ahora bien, esta conciencia supone una cierta reinterpretación y originalidad que será necesario exponer.

\section{La doctrina gaosiana de la "circunstancia"}

En esta reinterpretación de la doctrina son claves las palabras de Gaos que antes reproducimos sobre la necesidad de salvación de sí propio "intentando la salvación de la enorme circunstancia que para él era el maestro".

Por los años de la República, y antes, se había planteado en España la polémica sobre el valor filosófico de la obra de Ortega, que muchos le negaban plenamente, considerándole como de interés exclusivamente literario, todo lo alto que se quiera pero sin pasar nunca las fronteras de la mera literatura.

Ya entonces salió Gaos al paso de la desvalorización filosófica de su maestro, que creía originada por la forma periodística --"aquellos folletones de $E l$ Sol, de atractiva memoria"-, y propone ante la incomprensión con que se había recibido su primera obra - Meditaciones del Quijote- el siguiente experimento: "arranque el lector del citado libro el prólogo y la meditación preliminar, poniéndoles una cubierta que diga: Ensayo de una nueva teoria de la realidad y de la filosofia. Lea el volumen así reeditado por él -añade Gaos- y encontrará perfectamente justificado el título que le habrá puesto". ${ }^{18}$

La obra de reivindicación de la filosofía orteguiana representa algo mucho más importante que la de incorporar un pensador más - por muy impor-

17 "José Gaos: De la Filosofía de la Filosofía al personalismo escéptico", en Filosofia española en América (1936-1966), Ed. Guadarrama, Madrid, 1967 .

18 Pensamiento de lengua española, p. 284 . 
tante que sea- a nuestra historia. Se trata de reivindicar los valores anejos a las formas peculiares del pensamiento hispánico. La salvación de "la enorme circunstancia que era el maestro" es para Gaos caso paradigmático de algo más importante y profundo: la posibilidad misma de una filosofía hispánica, según los moldes con que ésta se había desarrollado en el pasado y que parecen más adecuados a la idiosincrasia de nuestros países. O, reproduciendo la interrogación que el mismo Gaos escribió: "¿Qué esperanzas puede tener un español de llegar a tener una filosoffa?". De esta interrogación surge la siguiente reflexión: "La negación de la índole de filosófico al "pensamiento' hispánico es conclusión de razonamientos que pueden sintetizarse en esta fórmula: Filosofía es la Metafísica de Aristóteles, la Ética de Spinoza, la Critica de la razón pura, la Lógica de Hegel.

"Es así que Los motivos de Proteo, Del sentimiento trágico de la vida, las Meditaciones del Quijote, La existencia como economia, desinterés y caridad, se parecen muy poco a aquellas obras.

"Luego éstas no son Filosofía.

"Mas, ¿por qué no razonar de esta otra manera?

"Los Motivos, El sentimiento, las Meditaciones del Quijote, La existencia se parecen muy poco a la Metafisica, a la Etica, a la Critica, a la Lógica. "Y son filosofías.

"Luego Filosoffa no es exclusivamente la Metafisica, etc., sino también los Motivos, etc".19

En el año 1950, Gaos comentando la obra de Eduardo Nicol, Historicismo y existencialismo, tropieza con la opinión de éste que le niega carácter de filósofo a Ortega. "Para la validez de la conclusión - comenta Gaos- me parece requisito la aplicación del mismo método a los demás filósofos, sin excluir a Nicol, con adopción de este criterio: si los resultados son los mismos la conclusión debe ser 'o todos o ninguno'; sólo si los resultados son exclusivos para Ortega, la conclusión debe ser 'todos menos él', descartada la posibilidad de que debiera ser 'ninguno más que él' ."

$\mathrm{Y}$ añade en interesante comentario a pie de página: "Un puro absurdo sería tal posibilidad - referida sólo a Ortega. Referida a los filósofos de su tipo, entraña una cuestión profunda y grave: la de la posibilidad de innovación en filosofía, es decir, la de la posibilidad de la historia misma de la filosofía. Se argumenta: filosofía es a, b, $c$-caracteres tomados a los autores de tipo $\mathrm{M}$; es así que la obra de los autores de tipo $\mathrm{N}$ no tienen esos caracteres, sino los caracteres $\mathrm{x}, \mathrm{y}, \mathrm{z}$; luego no es filosofía. Pero si no se argumenta así, la obra de los autores de tipo $\mathrm{N}$ no tiene los caracteres $\mathrm{a}, \mathrm{b}, \mathrm{c}$, sino los caracteres $x, y, z$; es así que es filosofía; luego filosofía no es a, b, c, exclusi-

10 Confesiones profesionales, pp. 119-114. 
vamente, sino también $\mathrm{x}, \mathrm{y}, \mathrm{z}$; sino se argumenta así, debiera considerarse la historia de la filosofía terminada - ¿dónde?".20

Hemos hecho esta segunda cita que aparentemente no hace más que reproducir el argumento de la primera, porque creemos que en ella se revela el problema que más de fondo le preocupó a Gaos durante toda su vida: el de las relaciones entre la Filosofía y su historia. Si en el párrafo extraido de las Confesiones profesionales, lo que le interesa más a Gaos es la reivindicación de los valores y las formas inherentes al pensamiento hispánico, en esta segunda cita el problema radical es el de hacerse una idea de la Filosofía que admita la innovación, es decir, la historicidad de sí misma. Ésta será la cuestión básica que servirá de origen e inspiración a toda la filosofía gaosiana: el problema de la unidad y pluralidad de la filosofía, que es el problema de su historia. A través de su preocupación por el pensamiento hispánico, Gaos desemboca en lo que ha sido el eje de su actividad intelectual: una Filosofía de la Filosofía que dé razón de sí misma y de la historicidad que comporta, sin dejar fuera ninguna de sus manifestaciones. "De lo que se trata - dice Gaos- en el fondo es nada menos que de lo siguiente: de confinar a la Filosofía en ciertas formas pasadas o de dejarle abierta la posibilidad de nuevas formas en el futuro." 21 No se trata, pues, tanto de justificar la actividad filosófica del pensamiento hispánico como de hacer posible la innovación y con ello la historicidad de la filosofía misma.

Este intento es el que le lleva a reinterpretar la teoría orteguiana de la "circunstancia" desde un punto de vista historicista. El programa de salvación de las circunstancias, propuesto por Ortega, no puede realizarse más que por medio de la cultura, y, sobre todo, por la razón, como expresión suprema de cultura. Pero, bien entendido que, si lo que hay que salvar es una circunstancia, dicha razón no puede entenderse como razón pura, sino como razón circunstanciada - un "logos del Manzanares", dice Ortega- o, para emplear su expresión definitiva: una "razón vital". Y esto en un primer nivel, porque posteriormente la circunstancia inmediata que es "nuestra vida" se revela constitutivamente histórica y, en consecuencia, la razón humana, se convierte en "razón histórica", mediante la cual va dando cuenta de sí misma y de la historia humana de que forma parte. "Esta conclusión - termina Gaos- basta para permitir darse cuenta del consecuente movimiento de ideas que llevó a Ortega desde el programa de la filosofía de las circunstancias, pasando por la concepción de la razón vital, a la concepción de la razón histórica." 22

20 Sobre Ortega y Gasset y otros..., p. 296.

21 Confesiones profesionales, p. 114 .

22 Sobre las vacilaciones de Ortega entre los conceptos de "razón vital" y "razón histórica" véase mi libro Ortega y Gasset en la filosofía española, Ed. Tecnos, Madrid, 1966, pp. 78 a 87 . En lo que toca a la evolución orteguiana del "circunstancialismo" a una teoría general de la vida humana y de su historicidad, véase todo el capitulo VI de dicho libro. 
Quizá esta reinterpretación gaosiana esté bastante de acuerdo con la evolución general del pensamiento de Ortega, a pesar de las vacilaciones que él mismo manifestó, pero no cabe duda de que mientras Ortega fue moviéndose cada vez más hacia una teoría de la vida humana en general y de su historicidad, ${ }^{23}$ Gaos reinterpreta todo ello a la luz de su "circunstancialismo" y "perspectivismo" primerizo, tomando la circunstancia en su mayor concreción, de acuerdo con un desarrollo cada vez más "personalista" de la filo sofía de su maestro. Esto aparecería de conformidad con las declaraciones del propio Gaos que se tiene por discípulo predilecto de Ortega durante la primera época, pero alejado de él físicamente - ¿y en qué medida esa "circunstancia" pudo afectar a la asimilación de la filosofía del maestro por el discípulo? - durante la segunda. En cualquier caso, es evidente que la interpretación gaosiana de Ortega está fuertemente influida por el "circunstancialismo" de la primera época del maestro, mientras la posterior evolución orteguiana se reinterpreta a la luz de dicha primera época.

Por lo demás, con dicha reinterpretación Gaos habria conseguido resolver su problema: salvar la enorme circunstancia que para él era el maestro Ortega, y a su vez, con ello, salvar las formas peculiares del pensamiento hispánico. Así hablando de la forma periodística en que Ortega solía exponer algunas de sus mejores y más profundas ideas: "No por tal forma de su obra no ha sido Ortega filósofo. Por ella ha sido del linaje de los filósofos que figuran en toda Historia de la Filosofía y que se sirvieron de las mismas formas, o de las equivalentes en sus circunstancias, para fines a los que son comparables los de Ortega. Pienso preferentemente, no exclusivamente, en los filósofos del siglo xviI, y tampoco exclusivamente en los franceses. Aquellos filósofos concibieron, ejecutaron y publicaron su filosofía como un medio de rehacer conforme a los dictados de la razón, del señorio de la luz sobre sí mismo y su contorno, la organización, la vida toda, de sus paises y aún de todos los países. $\mathrm{Y}$ acaece que tales filósofos son los verdaderos antecesesores de los que llamamos 'pensadores' en nuestros países, desde un P. Feijoo hasta un Unamuno y un Ortega en España; desde un Andrés Bello hasta un Martí, un Rodó, un Antonio Caso, en esta América. Estos pensadores fueron desde los primeros, siguen siendo los aún vivos, verdaderos padres de las respectivas patrias y aún cada uno de las patrias de los demás, de las patrias hispánicas todas, en el sentido de maestros de los respectivos pueblos, de maestros de los pueblos todos hispánicos. En este sentido, Ortega no es sino uno más entre los integrantes de tan ilustre casta." 24

El ciclo ha sido cerrado; de la salvación de Ortega a la justificación o salvación de la peculiaridad del pensamiento hispánico en general. El mismo Gaos así lo ve claramente, con una claridad con que no lo vio ni vislumbró

23 Sobre Ortega y Gasset y otros..., p. 107.

24 Sobre Ortega y Gasset y otros..., p. 108. 
siquiera Ortega: "El programa -dice- de salvaciones de las circunstancias españolas, de salvación de la circunstancia española, era un programa original, y de fecundidad indefinida, de filosofía española -expresamente; potencial o virtualmente, hispanoamericana en general: la filosofía de lo español, la filosofía española; la filosofía de lo hispanoamericano, la filosofía hispanoamericana." 25 Ahora, sí; ahora el camino está libre para lo que va a constituir la ocupación y preocupación principal de Gaos desde su instalación en América el año 1938, como lo reconoce él mismo: "lo que en España no había pasado aún de un juicio, se convirtió aquí, en México, en la parte de mi labor que personalmente estimo como principal". ${ }^{26} \mathrm{Y}$ nosotros con él.

\section{Gaos y la historia de las ideas hispanoamericanas}

Una vez conseguida la justificación teórica de su ocupación con la Historia de las ideas en Hispanoamérica, Gaos va a realizar una tarea que perdurará como fundamental en la revalorización que en los últimos años se ha hecho del pensamiento hispanoamericano. En esta tarea la labor originaria y más importante se centra en torno al Seminario para el Estudio del Pensamiento en los Países de Lengua Española, que primero funcionó dentro de La Casa de España en México y después en El Colegio de México, en que aquella se transformó. La dirección del Seminario por Gaos, culminó en la elaboración de tesis de donde salieron algunos de los mejores trabajos que sobre Historia de las ideas hispanoamericanas se han hecho últimamente; dos volúmenes de Leopoldo Zea, El positivismo en México y Apogeo y decadencia del positivismo en México; un trabajo aún no publicado, Algunas aportaciones al estudio de Gamarra o el eclecticismo en México de Victoria Junco. Los dos de Zea acaban de aparecer impresos en un solo volumen con el titulo de El positivismo en México. Nacimiento, apogeo y decadencia (1968). Además han publicado sus tesis: Monelisa Lina Pérez-Marchand, Dos etapas ideológicas del siglo xviii en México, a través de los papeles de la Inquisición; Bernabé Navarro, La introducción de la filosofia moderna en México; Olga Victoria Quiroz Martínez, La introducción de la filosofía moderna en España; Luis Villoro, Los grandes momentos del indigenismo en México; Vera Yamuni, Concepto e imágenes en pensadores de lengua española; Francisco López Cámara, La génesis de la conciencia liberal en México; Carmen Rovira, Eclécticos portugueses del siglo xviii y algunas de sus influencias en América.

A lo largo de sus tareas en la dirección del citado Seminario, Gaos ha ido

25 Pensamiento de lengua española, p. 75.

26 Confesiones profesionales, p. 113 . 
forjando, mediante su influencia personal en los alumnos, un grupo de intelectuales que van a seguir interesándose y trabajando sobre el pensamiento hispánico. Entre ellos, la mayoria es de mexicanos, pero algunos de ellos no lo son. Por ejemplo, Monelisa Lina Pérez-Marchand, puertorriqueña, que actualmente es profesora en la Universidad de su pais; el brasileño Pero Adjucto Botelho; el norteamericano John L. Groves; y, sobre todo, el peruano Augusto Salazar Bondy, que trabajó en el Seminario sobre su compatriota Hipólito Unanue, y autor posteriormente de una Filosofia en Perú: panorama histórico, una Historia de las ideas en el Perú contemporáneo, además de un librito, cuyo título - ¿Existe una filosofía de nuestra América?indica claramente su interés por el tema.

Naturalmente, la mayoría de los discípulos de Gaos son mexicanos: Edmundo O'Gorman, Justino Fernández, Manuel Cabrera, Luis Villoro, se declaran discípulos del maestro español, aunque el más obviamente tal - por reconocimiento expreso de ambos- es Leopoldo Zea, que ha continuado con éxito cada vez creciente las tareas gaosianas de investigación sobre pensamiento hispánico: Aparte sus magníficos estudios sobre $E l$ positivismo en México, sobre América en la historia, y sobre numerosos otros temas afines, Zea destaca como promotor de investigaciones sobre "Historia de las ideas en América", dentro de la colección Tierra Firme del Fondo de Cultura Económica, de México. Esta colección está compuesta por las investigaciones respectivas de los diferentes especialistas a quienes se encargó del trabajo para cada país de América: Arturo Ardao, para Uruguay; Guillermo Francovich, para Bolivia; Humberto Piñera, para Cuba; João Cruz Costa, para Brasil; Jaime Jaramillo Uribe, para Colombia; Angélica Mendoza, para Estados Unidos; Rafael Heliodoro Valle, para Centroamérica; Mariano Picón-Salas, para Venezuela; José Luis Romero, para Argentina; Luis Oyarzun, para Chile; Leopoldo Zea, para México. Este proyecto de investigación y publicaciones fue fruto de la colaboración entre el Comité de Historia de las Ideas en América presidido por Zea, Sección a su vez de la Comisión de Historia del Instituto Panamericano de Geografía e Historia, y el citado Fondo de Cultura Económica, mediante la ayuda prestada por la Fundación Rockefeller. El plan no ha sido llevado a cabo en su totalidad hasta la fecha, pero con lo que hasta el momento existe, ya se puede afirmar sin duda que es punto obligado de referencia y de consulta para el que se interese por la historia de las ideas en América.

Pero no sólo a través del Seminario para el Estudio del Pensamiento de los Países de Lengua Española, y de su discípulo, logra Gaos una influencia persistente en la creación de un clima de interés y dedicación por la historia del pensamiento hispanoamericano, sino mediante contribuciones escritas personales, algunas de ellas de extraordinario valor. Entre ellas, y en primer lugar, citaremos la labor de crítica de las distintas obras publi- 
cadas sobre el tema. Si repasamos los indices de Sobre Ortega y Gasset y otros trabajos de historia de las ideas en España y la América española, vemos artículos dedicados a "La filosofía en Bolivia", "La filosofía en Cuba" y "La filosofía en Uruguay", que son respectivas notas críticas a los libros que sobre el tema han publicado Guillermo Francovich, Medardo Vitier y Arturo Ardao. Pero ya mucho antes había dedicado Gaos artículos a diferentes aspectos -obras, autores, movimientos- del pensamiento hispánico, que habían sido recogidos en libros como Pensamiento de lengua española (1945), El pensamiento hispanoamericano (1944), o los dedicados al tema en México: En torno a la filosofía mexicana (2 vols. 1952 y 53 ) y Filosofía mexicana de nuestros dias (1954), de los que nos ocuparemos más extensamente después. Lo más importante de tales publicaciones, es la situación y caracterización que Gaos hace tanto del pensamiento hispanoamericano en general, como del mexicano en particular, pero temas ambos de tanta trascendencia que no tenemos más remedio que dedicarles un apartado por separado a cada uno de ellos. Por último, no queremos terminar esta nota sobre la concreta labor de Gaos en la potenciación de la historia de las ideas hispanoamericanas, sin hacer alusión a sus iniciativas de antologista y autor de intere santes reediciones. Entre estas últimas citaremos la magnífica edición de la Filosofía del entendimiento, de Andrés Bello, con una introducción muy extensa, que es sin duda el mejor estudio que existe sobre tal obra. Merece citarse también la traducción y selección de los Tratados, de J. B. Díaz de Gamarra, que Gaos hizo con toda meticulosidad, añadiendo un prólogo suyo y numerosas notas a pie de página. De las antologías, y dejando a un lado la breve sobre Pensamiento español (1945) por ser más bien un texto de lectura, es digna de nota la Antologia del pensamiento de lengua española en la Edad Contemporánea (1945), pues la inclusión del pensamiento español e hispanoamericano juntos obedece a motivos muy profundos de lo que ambos sean, de su caracterización y de su sentido en la historia; todo lo cual requiere el tratamiento aparte de que antes hablábamos al referirnos a las obras de Gaos sobre el tema.

\section{México y el pensamiento mexicano}

La actitud de Gaos ante el pensamiento mexicano es un caso particular de la que tomó ante el pensamiento hispanoamericano en general, pero que tiene especial interés por la atención y dedicación singular que Gaos dedicó al mismo. Es indudable que en ello influyó decisivamente el haberse radicado el maestro español en México, pero no menos decisiva fue la espléndida recepción que dicho país hizo a los "refugiados" españoles de la guerra civil. En numerosos casos -podría decirse que siempre que la ocasión se le ha 
presentado-, ha expresado Gaos su agradecimiento por la recepción mexicana, lo mismo a los políticos más altos, empezando por el entonces Presidente de la República, don Lázaro Cárdenas, hasta los intelectuales más conspicuos del momento - Antonio Caso, Alfonso Reyes, Daniel Cosío Viliegas, Jesús Silva Herzog - y los compañeros de la filosofía que en pie de igualdad compartieron con ellos tareas de enseñanza y edición en instituciones como la Facultad de Filosofía y Letras, de la Universidad Nacional Autónoma de México; la Universidad Femenina de México; la Casa de España en México, fundada por el Presidente de la República exclusivamente para patrocinar a los intelectuales españoles recién llegados al pais, y que más tarde se convirtió en El Colegio de México; el Fondo de Cultura Económica; Cuadernos Americanos; y otras instituciones, de que Gaos ha hecho el recuento en un ensayo digno de ser conocido. ${ }^{27}$ Pero el agradecimiento de Gaos por México no se limitó, en cualquier caso, a mera expresión verbal, sino que puso lo mejor de sí mismo en la potenciación de la filosofía y los filósofos mexicanos, al objeto de, según sus propias palabras, "poder pagar aún las deudas parciales de la total e impagable deuda con México"..28 En todos sus prólogos se encuentra casi siempre la huella de esa conciencia deudora, si bien quizá nunca de forma tan expresa como en el siguiente párrafo: "México salvó la vida, la vida intelectual, que para el intelectual es la vida pura y simplemente, de los numerosos intelectuales españoles que se sabe. Sería para mí motivo de la más fruitiva satisfacción que se pudiera reconocer cómo de mi parte he hecho todo.lo factible por corresponder según era debido." 29 Esta extraordinaria recepción mexicana no pudo menos de obrar en el ánimo de los españoles, creando una peculiar vivencia que José Gaos ha expresado acertadamente con el neologismo de "transterrados", por oposición al nombre acuñado de "desterrados"; con ello se pretende expresar el sentimiento peculiar de haberse instalado en una tierra, que sin ser como la abandonada, tampoco resulta ser completamente extraña, en la que la nueva vida se siente como una prolongación de la anterior. He aquí cómo lo expresa el propio Gaos: "En los españoles actuó, sin duda, desde un principio, la emigración. Con una actuación de dos vertientes. Toda emigración representa una experiencia vital tan importante como no puede menos de ser la experiencia de emprender una vida más o menos nueva. Pero una emigración forzosa representa la experiencia de emprender una vida más o menos nueva en una peculiar relación con la vida anterior. Como ésta se dejó por fuerza y no por prever otra vida preferible y resolverse a vivirla, se vive la vida nueva con una singular fidelidad, entre efectivamente espontánea y moralmente debida, a la anterior, lo que da de sí una poten-

27 Pensamiento de lengua española, p. 11.

28 "Los transterrados españoles de la filosofía en México", en Filosofía mexicana de nuestros dias; México, 1954.

20 Filosofia mexicana de nuestros dias, p. 14. 
ciación de lo que retenía en ésta, lo valioso de ella, menos notorio en lo habitual de la posesión que en lo al pronto insólito de la pérdida, y en lo engrandecedor, que no empequeñecedor, de la distancia temporal en el recuerdo. Esto puede ser aún en el caso de que el asiento en la nueva tierra resulte preferible al retorno a la dejada, cuando entre valores de una y valores de otra cabe ver una relación que permita conciliar la fidelidad a los unos con la adhesión a los otros. Es lo que nos ha pasado a los españoles en México. Porque, y ésta es la otra de las vertientes anunciadas, los españoles hicimos un nuevo descubrimiento de América. 'Sabíamos' de la América española, pero qué diferente 'vivir' su vastedad y diversidad en el presente, su profundidad y complejidad por el pasado y a una su juventud, su fermentar de formación, y por las tres cosas su plétora de posibilidades de futuro. Pero nosotros habiamos iniciado ya en España la actividad de que estoy tratando. Es que la reivindicación de los valores españoles había empezado en España, movilizada justamente por la conciencia de su valer. Esta conciencia era parte para que no previésemos otra vida preferible y la posibilidad de dejar la que vivíamos, posibilidad en que no pensamos, hubiese de realizarse sólo como se realizó, por la violencia. Por fortuna, lo que hay de español en esta América nos ha permitido conciliar la reivindicación de los valores españoles y la fidelidad a ellos con la adhesión a los americanos." ${ }^{30}$ Esta adhesión de Gaos a los valores de su nueva tierra americana, es sentida por él como una identificación con la nación mexicana, su lugar de asentamiento, según ha expresado en otro lugar al hablar del mismo tema, con palabras que recogeré aquí nuevamente: "En esta identificación con la nación mexicana, Gaos ha llegado a formular su teoría de las dos patrias: la de 'origen', que nos viene dada por un azar más allá de toda decisión personal, y la patria 'de destino', libremente elegida por coincidir con el proyecto de vida que voluntariamente nos hemos impuesto. Entre España,. 'patria de origen', y México, 'patria de destino', Gaos parece complacerse en una aceptación espontáneamente vivida de la segunda." 31

Aunque, al principio, impuesta por la violencia, como decía antes Gaos, esta posterior aceptación espontánea de su destino le lleva a Gaos a interesarse por las producciones intelectuales mexicanas, origen de sus libros sobre el tema: En torno a la filosofia mexicana (1952-53), Filosofia mexicana de nuestros dias (1954), aparte de los trabajos incluidos en Pensamiento de lengua española (1945). Sería de indudable interés ir analizando una por una las contribuciones gaosianas a la historia de las ideas en México en cada uno de estos libros; contribuciones que van desde la nota crítica sobre un libro -muy frecuentemente-, hasta un estudio serio y detallado sobre un tema, como el magnifico sobre "El sistema de Caso" (en Filosofia mexicana de

30 Ibid., pp. 312-313.

31 Filosofía española en América (1936-1966), pp. 23-24. 
nuestros dias) o sobre "El pensamiento hispanoamericano" (en Pensamiento de lengua española), pasando por prólogos, conferencias, presentaciones de libros -actividades naturales todas ellas en un pensador "de circunstancias", como era y pretendía ser José Gaos. Las numerosas actividades filosóficas y el interés apasionado que Gaos puso en ellas son pruebas de la fidelidad con que vivió su "circunstancialismo" filosófico. $\mathrm{Y}$ por muy deleznables que tales actividades puedan parecer, un repaso ligero a unas cuantas de ellas nos revelará la densidad, la honradez y la extraordinaria fecundidad que las mismas pueden revestir. Para citar sólo una de ellas, una de las más desconsideradas entre nosotros - la de crítico de libros- recordemos que al libro de Eduardo Nicol, Historicismo y existencialismo, le ha dedicado dos estudios, uno de ellos de 53 páginas densas y de letras menudas, y a los trabajos de lógica jurídica de García Máynez, cerca de 40 del mismo estilo, con las naturales y valiosisimas consecuencias para el lector o estudioso del libro, tanto como para el autor del mismo. Los límites que nos hemos trazado en este trabajo nos impiden ir deslindando y analizando un tema que habría de ser tan largo y minucioso como interesante y fructífero.

Uno de los modos por los que la influencia de Gaos en México habría de ser más fuerte y perdurable, es a través de sus alumnos y discipulos, de los que ya anteriormente hablamos. Entre ellos logró el maestro despertar un interés cada vez mayor por la historia del pensamiento y la filosofía mexicana, que ha ido concretándose en un tema: el de la filosofia de lo mexicano, que, como luego veremos, si logró la aquiescencia del maestro, fue con reparos y bajo ciertas condiciones.

Aunque Gaos reivindica para Alfonso Reyes la prioridad en el movimiento que tiene como tema lo que podríamos llamar "búsqueda del alma nacional mexicana" y en Samuel Ramos un antecedente clarísimo del mismo movimiento, no deja de reconocer que es su discípulo, Leopoldo Zea, quien aglutina de forma consciente y radical en sus distintas variantes, mediante la fundación del llamado "Grupo Fílosófico Hiperión", con la colaboración de Ricardo Guerra, Joaquín Macgregor, Jorge Portilla, Salvador Reyes Nevares, Emilio Uranga, Fausto Vega y Luis Villoro. Este movimiento filosófico "Hiperión", dirigido por Zea, tiene como órgano de expresión la colección "México y lo mexicano", que tuvo su aparición pública con el volumen de Alfonso Reyes, La X en la frente (Algunas páginas sobre México), al que siguió el libro de Zea, Conciencia y posibilidad del mexicano. En el cítado primer volumen hay una "Advertencia" de Zea, fundador. y director de la colección, que dice entre otras cosas: "Un sorprendente, y cada -vez más creciente, interés de los mexicanos por México, lo Mexicano y el Mexicano ha dado lugar a lo que los historiadores llaman un 'clima' en torno a estos problemas. Trátase de un movimiento tendente a captar el espíritu de México, el sentido de lo Mexicano y el ser o modo de ser del hombre de esta 
realidad. Este 'clima' se ha desplazado del mundo puramente académico llegando a través de diversas vías, al hombre llamado 'común'... Esta popularización de los temas sobre México, lo Mexicano y el Mexicano ha conducido en muchas ocasiones a falsas interpretaciones... que han originado disputas y disputas sobre disputas. Por esta razón se hacía necesaria una Colección... en la que se expusieren, en forma concreta y asequible, los diversos enfoques que se han venido dando a estos temas en esta etapa de conciencia de nuestra realidad." El proyecto gozaba de la simpatía de Gaos, como lo manifestó en su ensayo "México, tema y responsabilidad", ${ }^{32}$ puesto que él mismo lo había alentado en cierto modo; ¿de dónde, entonces, esos reparos y condiciones de que antes hablábamos? Pero, antes de contestar a esta pregunta será conveniente exponer, siquiera sea someramente, la actitud de Gaos respecto de la historia en general de la filosofía en México. A pesar de numerosos intentos realizados no hemos podido conseguir, ni siquiera consultar, los dos tomos en que, bajo el título En torno a la filosofia mexicana, Gaos expone su visión de la historia de la filosofía en México, teniendo por tanto que atenernos a lo que en su conferencia, "Lo mexicano en filosofía", dice sobre el tema; creemos poder así extraer al menos lo esencial de su pensamiento.

En primer lugar, debemos destacar la intención con que Gaos hace este repaso a la filosofía mexicana, y no es otra que la de verificar la verdad o falsedad del juicio que asegura que México no ha hecho ninguna aportación a la filosofía universal, habiéndose limitado a importar filosofías extranjeras. Gaos duda, sin embargo, de que la importación de filosofías sea un hecho puramente receptivo y no haya en él al menos un mínimo de actividad aportativa. Bien pudiera considerarse así la mera importación de filosofía escolástica durante la primera época de la colonia. No ocurre esto desde la mitad del siglo xvir, en que los jesuítas y algunos que no lo son, como Gamarra, seleccionan con criterio electivo tales filosofias, y este criterio no puede ser otro que el de su valor para las necesidades y circunstancias del país. Este crucial momento del xviI, marca dos etapas diferentes en el carácter importador de las filosofias extranjeras, que si primero se hacen desde fuera con espiritu metropolitano que se impone a la colonia, en un segundo momento se importà desde dentro con espiritu de espontaneidad, independencia y personalidad nacional y patriótica creciente. Este criterio electivo es el que marca la importación de la filosofía liberal en la primera mitad del siglo xrx, de la positivista en la segunda mitad de dicho siglo y de los movimientos espiritualistas y antipositivistas en las primeras décadas de este siglo.

Pero estas importaciones activamente electivas, no se limitan en muchos casos a ser sólo tales, sino que se adaptan a las peculiaridades culturales del

32 Filosofia mexicana en nuestros dias, pp. 191-216. 
país en su momento para lograr una plena y fecunda inserción en lo nacional. Y en casos relevantes - por ejemplo, el de Gabino Barreda en su oración cívica de Guanajuato el 16 de septiembre de 1867 - se pasó más allá todavía: a una inserción de lo nacional en lo innovador y hegemónico, lográndose así importaciones aportativas entre las que Gaos destaca la filosofía de la existencia de Antonio Caso y la filosofía estética de José Vasconcelos, a las que considera dignas de figurar en cualquier Historia de la Filosoffa, a pesar de la ignorancia que hasta los mismos mexicanos tienen de las mismas. "¿Cuál es la sinrazón de semejante injusticia de la Historia de la Filosofía con la filosofía mexicana, de los no mexicanos con los mexicanos, de éstos consigo mismos?" Y la contestación no se hace esperar: "Un doble hecho, político y cultural: la dependencia política de América respecto de Europa y la dependencia de las valoraciones culturales respecto de las políticas." ${ }^{33}$ Ahora bien, la reparación de una tal injusticia depende fundamentalmente de la evolución de la filosofía en México y de lo que los filósofos mexicanos hagan, actividad que necesariamente revertirá sobre su pasado y la valoración del mismo. Recordemos, sin embargo, que la actividad filosófica actual ha recaído sobre el empeño de articular una "filosofía de lo mexicano", a la que Gaos -aun siendo promotor de la misma- había puesto ciertos reparos.

Estos reparos provienen en su totalidad de la motivación última que subyace bajo el afán de tal filosofía de lo mexicano, y dicha motivación no es otra que la pretensión de una filosofía mexicana original. "Mas es obvio -dice Gaos- que si sobre lo mexicano filosofasen no mexicanos, el resultado no sería la filosofía mexicana de que se experimenta afán." La mexicanidad de una filosofía no puede provenir del tema tratado, sino de la idiosincrasia nacional y personal de sus autores. Por ello dice Gaos, resumiento su pensamiento: "Filosofía de mexicanos sobre cualquier objeto no puede menos de tener una especificidad característica, en la medida en que la filosofía tampoco puede menos de realizarse en filosofías expresivas de la personalidad, no sólo étnica, sino hasta individual, de los respectivos autores, y en que los mexicanos filosofantes tienen sin duda esta doble personalidad. La cuestión parecería ser, pues, que mexicanos filosofasen -sobre cualquier objeto." 34 Por lo demás, Gaos nada tiene que oponer al tratamiento del tema, cuando se deja de identificar filosofía mexicana y filosofía de lo mexicano, y ésta aparece como uno de los múltiples temas de las concéntricas circunstancias mexicana y universal, a que todo filósofo mexicano debe hacer frente. Es la línea seguida por Alfonso Reyes y por Leopoldo Zea, en cuya competencia y buen sentido Gaos tiene plena confianza; ellos se ocupan también de problemas mexicanos, pero sin olvidar su inserción

33 Ibid., p. 348 .

34 Ibid., pp. $35^{1-352 .}$ 
en la temática universal y sin creer que por hablar mucho de México y lo mexicano - filosofía de lo mismo- se es más mexicano que si no se habla de ello; la mexicanidad de la filosofía, como de lo demás, vendrá dada por la personalidad étnica e individual de los sujetos que traten temas -que no tienen por qué ser mexicanos.

En este punto Gaos no ha hecho más que aplicar lo que ya en los primeros años en México había hecho público en un "cuarto a espadas" sobre el tema que ya entonces se debatía ampliamente: "¿Filosofía 'americana'?" Empieza Gaos dicho artículo con estas palabras: "A lo largo del año que acaba de morir se ha debatido en estos países americanos de lengua española el tema de la creación de una filosofía peculiar de ellos. Se desea llegar a tener una filosofía mexicana o argentina, o americana, como hay una filosofía francesa, alemana o europea." $Y$ tras admitir lo que no parece tan claro - que sea deseable tener una filosofía propia- Gaos concluye tajantemente en el mismo sentido anterior, aunque si antes se refería sólo a lo mexicano, ahora su argumento tiene un carácter más general: "la filosofía griega o la francesa o la alemana no son tales porque los filósofos griegos, franceses o alemanes se hubiesen propuesto que tales fuesen, ni menos la filosofía europea porque se lo hubiesen propuesto los filósofos europeos, sino porque unos griegos, franceses, alemanes o europeos en general, hicieron filosofía. La filosofía resulta de la nacionalidad o la 'continentalidad', sit venia verbo de sus autores, quizá incluso a pesar de ellos, sin más que ser filosofía, pero auténtica. Si españoles, mexicanos o argentinos, hacen suficiente filosofia, sin más habrá filosofía española, mexicana, argentina, americana. ¿Perogrullada? Quizá necesaria... la filosofía ¿sería original de suyo, por su naturaleza? ¿Filosofía (si auténtica) $=$ original? ... La cuestión no está, pues, en hacer filosofia española o americana, sino en hacer españoles $o$ americanos filosofía. De lo que hay que preocuparse no es, en fin, de lo español o lo americano, sino de lo filosófico de la filosofía española o americana." 35

Sin embargo, estas afirmaciones parecen dar por sentado la no existencia de una filosofía americana propiamente dicha, lo que contradice afirmaciones posteriores de Gaos, como hemos visto ya, pero sobre todo como veremos con más detalle a continuación en la exposición de los caracteres del pensamiento hispanoamericano, lo que tácitamente implica la existencia del mismo. Ahora bien, ¿cuáles son esos caracteres? Es lo que vamos a examinar inmediatamente.

\section{Caracteres del pensamiento hispanoamericano}

El lugar donde de forma más detallada expone Gaos su pensamiento so 35 Pensamiento de lengua española, pp. $355 \cdot 361$. 
bre el tema es en el ensayo "El pensamiento hispanoamericano. Notas para una interpretación histórico-filosófica", incluido como trabajo principal del libro de que ya hablamos anteriormente, Pensamiento de lengua española (México, 1945). En esta exposición va por grados de profundización sucesiva: de una localización histórica, a una caracterización formal y material y a una interpretación de su significado filosófico.

En la localización histórica, hace Gaos una serie de consideraciones y delimitaciones geográficas, entre las cuales la de mayor interés para nosotros es la extensión que da al término "Hispanoamérica", en la que incluye tanto a la metrópoli como a la colonia, a España como a la que Gaos llamará la América española. En general, en los términos Ibero-América, Luso-América, Anglo-América, comprende, junto a las entidades del continente americano, las que fueron sus metrópolis europeas, reservando para aquéllas los nombres de América ibérica, América portuguesa y América inglesa. ${ }^{36}$

Aqui nos limitaremos al caso de Hispanoamérica, en el que Gaos descubre una doble etapa histórica: la de la dependencia colonial de los países americanos con respecto a España y la de la independencia nacional de aquellos. Ahora bien, la independencia política de las naciones americanas con respecto a la metrópoli española se da dentro de un movimiento general de independencia ideológica: de las colonias respecto de su pasado y de España respecto de sí misma.

Este movimiento de independencia, que se origina en el siglo xvirl, impulsado por la corriente europea de la Ilustración, tiene una misma dirección concordante: "En España, un movimiento de renovación cultural, de reincorporación después de la decadencia inmediatamente anterior, de revisión y crítica del pasado que había concluido en aquella decadencia. En las colonias, en México señaladamente, un movimiento de renovación cultural asimismo, de independencia espiritual respecto de la metrópoli, de la consecuente tendencia, siquiera implícita, a la independencia política." 37 Hemos hablado de la dirección concordante de ambos movimientos, pues efectivamente en ambos de lo que se trata es de lograr una independencia del pasado: la colonia respecto de la metrópoli y la metrópoli respecto de si misma. Pero en la medida en que metrópoli y colonia se implican en un común èspíritu imperial, de lo que tratan ambos es de huir del pasado imperial, del Imperio, en suma. El pensamiento hispanoamericano es, pues, liberal y antiimperialista. He aquí la dirección concordante a que aludíamos. Por eso cuando se trata de hacer una antologia del pensamiento hispanoameri-

36 En lo que resta, cuando empleemos los términos "Hispanoamérica" o "hispanoamericano" lo haremos en el sentido gaosiano, es decir, incluyendo "España" o "español" dentro de su contenido. En este sentido, Hispanoamérica comprende todos los países de lengua española; e hispanoamericano es todo habitante de un país de habla española, sea mexicano, argentino, español, etc.

37 Pensamiento de lengua española, p. 25. 
cano, Gaôs incluye dentro de la misma a la parte más representativa del pensamiento español, y así la nueva obra se llamará Antologia del pensamiento de lengua española (México, 1945).

Ahora bien, este movimiento de independencia espiritual conduce a la independencia política de los países americanos, mientras fracasa -como movimiento político- en la Península. "España - dice Gaos- es la última colonia de sí misma, que de sí misma, la única nación hispanoamericana que del común pasado imperial, queda por hacerse independiente, no sólo espiritual, sino también políticamente." ${ }^{38} \mathrm{Y}$ habiendo identificado la nueva España, al menos en el plano político, con la Segunda República española, añade: "El movimiento que terminó con la Segunda República española practica rigurosa consecuencia histórica invocando el Imperio." 39 Aún así Gaos está convencido de que, hasta políticamente, la vieja España era ya la de menos fuerza, y el movimiento que triunfó contra la República nunca lo hubiera logrado sin contar con el apoyo de potencias extranjeras. Así orientada la evolución histórica, hay que sacar la consecuencia de que la verdadera separación a establecer no es la meramente geográfica entre metropolitanos y coloniales, sino la más compleja entre metropolitanos y coloniales representantes y partidarios del pasado y los unos y otros representantes y partidarios de un nuevo presente y futuro.40

Este movimiento de independencia espiritual encuadrado, como antes dijimos, dentro del cuadro ideológico de la Ilustración, triunfa en Europa durante el siglo xvin, y tiene como nota radical la tendencia al "inmanentismo" creciente en la filosofia occidental. Este inmanentismo se caracteriza muy fundamentalmente por una ocupación con las cosas de este mundo y de esta vida, en su máxima concreción. Entre estas cosas destaca la preocupación por la realidad nacional y su cultura. "La Ilustración hace que en España se plantee, que España se plantee el tema 'España': el tema de la grandeza y decadencia de España, de la historia y la esencia de España, con las correspondientes crítica y terapéutica, la principal la ilustración, la visión de las luces extranjeras como operación difusiva de ellas en el país." 41 Y lo mismo ocurre en el continente americano; los intelectuales de aquellos paises - Bolívar, Sarmiento, Montalvo, Martí, Rodó, Vasconcelos- se plantean el tema "América"; en nuestro pais, Larra, Costa, Ganivet, Unamuno, el 98, Ortega, se habian planteado el tema "España". Sólo así localizado en la historia, es posible caracterizar adecuadamente el pensamiento hispanoamericano.

En esta caracterización destaca Gaos una serie de notas definitorias del pensamiento hispanoamericano, entre las que señala muy por encima de las demás, el rasgo estético, tanto en su aspecto formal como material; caracte-

88 Ibid., p. 28.

39 Ibid., p. 29.

40 Ibid., p. 32.

41 Ibid., pp. $45-46$. 
rística que ha llevado erróneamente a tildar tal pensamiento de "meramente literario". Esta característica estética se da en las formas de expresión y comunicación preferidas por tales pensadores: las formas orales, como son la conferencia y el discurso hasta la conversación y la tertulia, donde a veces tiene el pensador sus logros más plenos; los géneros más literarios: el artículo de revista y de periódico; y hasta el cultivo de la literatura de imaginación, inseparable de la de pensamiento, en Unamuno, Ganivet, Vasconcelos, Martí, como en Europa tendríamos un caso similar en el Sartre de nuestros días; la preocupación por el estilo, por un estilo literariamente bello, lo que origina que con frecuencia coincidan nuestros pensadores con nuestros mejores prosistas: Ortega y Martí, casos quizá más representativos. Ahora bien, esta característica estética no se da sólo en el aspecto formal, sino en el contenido doctrinal de los escritos, que en su mayoría cae dentro del ámbito de la estética concreta o aplicada (muy preferentemente la crítica literaria y de arte), pero también dentro de la doctrina estética y de las ideas estéticas, hasta llegar incluso a visiones del mundo y sistemas filosóficos de inspiración y culminación estética, como los de Deustua y Vasconcelos. Por último, hay una tercera acepción de lo estético que consiste en el tratamiento de lo estético, junto con lo no-estético, aunque con un proceder y una intención que no puede sino calificarse de estética.

Además de la nota estética, el pensamiento hispanoamericano tiene otras notas definitorias quizá menos importantes, pero esenciales para una caracterización, si no completa, suficiente. Estas notas son: la política y la pedagógica, ambas entendidas en un sentido amplio y no con la acepción restringida que se les suele dar. En lo que toca a lo politico es clara la preocupación por la organización político-cultural, por el frecuente tratamiento de temas políticos y hasta por la intervención directa en la política activa: Costa, Unamuno, Ortega, en España; Bolívar, Sarmiento, Martí, en América, por poner sólo tres ejemplos máximos en la Península y el Continente. $\mathrm{Y}$ en lo referente a la nota pedagógica, entendida también en un sentido amplio, un repaso a los principales pensadores hispanoamericanos nos hace ver enseguida una predilección por la literatura y la obra pedagógica, pero más todavía un pedagogismo difuso en el espíritu general de su producción. Muchos de ellos fueron profesores, otros sintieron el anhelo de conducir a sus pueblos, pero todos ellos sintieron el afán ético de la reforma, del cambio o de la "regeneración" nacional, como a finales del xix se decía en España, hasta originar un movimiento propio. Y si queremos ejemplos, el problema no es encontrarlos, sino seleccionar los más significativos: desde la Misión de la Universidad, de Ortega, o la Educación popular, de Sarmiento, hasta el "magistral" Ariel, de Rodó, los Discursos a la nación mexicana, de Caso, o "Mairena habla a sus alumnos" de Machado.

A través de estas notas definitorias, Gaos capta la unidad esencial y la 
característica radical del pensamiento hispanoamericano, que formula con estas palabras: "una pedagogía política por la ética y más aún la estética; una empresa educativa, o más profunda y anchamente 'formativa' -creadora o reformadora, de 'independencia', 'constituyente', o 'constitucional', de 'reconstrucción' 'regeneración', 'renovación'- de los pueblos hispanoamericanos, por medio de la 'formación' de minorías operantes sobre el pueblo y de la directa educación de éste; por medio, a su vez, principalmente, de temas específicamente bellos y de ideas, si no específicamente bellas, expuestas, como aquellos temas, en formas bellas, entre las cuales se destacan las de la palabra oral en la intimidad, la de la conversación". ${ }^{42}$ Y todo ello dentro de esa tendencia al "inmanentismo" que es propia de la filosofía occidental desde la Ilustración a nuestros días, en los que - por mucho que se hable de "renovación de la metafísica" - predomina el ametodismo, el asistematismo y lo antimetafísico, si no mero ametafisicismo.

Una vez así caracterizado el pensamiento hispanoamericano, pasa Gaos a indagar sobre su significación filosófica. Y para ello parte de la alternancia señalada por Dilthey en la historia de la filosofía entre épocas metafísicas por el fondo y sistemáticas y metódicas por la forma, y épocas de filosofía aplicadas a la moral y a los demás sectores de la cultura, frecuentemente ametafísicas o antimetafísicas, asistemáticas y ametódicas. "Este alterno ritmo no sería naturalmente casual -dice Gaos. Sería el ritmo respiratorio, vital, de la filosófica vida humana." 43 Ahora bien, esta alternancia entre "transcendentismo" e "inmanentismo" a Gaos no le parece simplemente tal, sino de un predominio creciente del inmanentismo desde la época de los griegos hasta la edad contemporánea, siendo el pensamiento hispanoamericano una manifestación voluminosa y original de dicho inmanentismo.

Desde este punto de vista, el juicio que nos merezca el pensamiento hispanoamericano dependerá de la postura que tomemos ante el pasado, lo que indefectiblemente revertirá sobre el futuro. Efectivamente, si consideramos como filosofía las "obras maestras" de la tradición filosófica donde se hallan los caracteres sistemático, metódico y metafísico, es evidente que el pensamiento hispanoamericano - con gran parte del pensamiento contemporáneo y hasta moderno- no puede ser considerado como filosófico. Pero muy bien pudiera ocurrir lo contrario, muy bien pudiéramos pensar que la filosofía no tiene que ver nada con tales caracteres, sino como antecedente prehistórico, y que las "obras maestras" de la filosofía no son aquellas donde se exponen "los grandes temas de la metafísica", sino todo lo contrario, las "superadoras" de la metafísica y del sistema, las monografías especializadas y ágiles de nuestro tiempo, donde se enfocan problemas concretos con una minuciosidad y una precisión, no por menos sistemática, menos rigurosa,

42 Ibid., p. 90.

43 lbid., p. 96. 
siendo por el contrario "los grandes sistemas metafísicos" reliquias supervivientes de un "arcaico y megalítico pasado humano".44 En esta tesitura, podríamos concluir todo lo contrario de lo que conclufamos anteriormente, de esta nueva forma: "El pensamiento hispanoamericano es filosofia; es así que sus obras no se parecen a las llamadas obras maestras de la filosofía; luego filosofía no es lo propio de estas obras." 45

Lo definitivo de todo esto es que los juicios acerca del valor y naturaleza del pensamiento hispanoamericano dependen de sí mismo, de lo que él decida en el presente respecto de su pasado. Según el criterio que apliquemos y según las posibilidades que en el presente actualicemos, el pasado, tanto como el futuro, serán uno u otro. "La filosofía pasada será filosoffa o no según las decisiones de la futura. Los maestros son hechos por los discípulos. El pasado, por el presente. Lo anterior, por lo posterior"..6 Asl en la historia. Y para terminar empleando una frase de Gaos: "la solución del problema de la naturaleza y valor, de la conceptualización del pensamiento hispanoamericano depende de la historia del pensamiento, presente y sobre todo futura, si ya no pasada".47

- Ahora queda una pregunta: ¿Cuál es la postura que Gaos adopta ante el dilema de dicho pensamiento? En una disección profesional y objetiva del problema, Gaos no puede ponerse en lugar de la historia y emitir un juicio profético, que estaría aquí fuera de lugar. Esto no quiere decir que no se vislumbren sus preferencias, máxime cuando por otras obras y por su actitud personal sabemos que Gaos tomó partido decisivo por el inmanentismo y con ello por la reivindicación del pensamiento hispanoamericano, única forma de "salvar" con la teoría su circunstancia de español-mexicano; que no hay contradicción en los términos y en este caso incluso complemento: español por mexicano y mexicano justo por español, podríamos decir con un estilo muy suyo.

Las preferencias gaosianas, sin embargo, se vislumbran, como deciamos antes, aquí y alli, y en algún momento se hace la ilusión de que el pensamiento hispanoamericano hasta pudiera tener "la originalidad y la plenitud de ser el extremo crítico del inmanentismo contemporáneo. Él pudiera ser el llamado a decidir al menos para sí, eventualmente para el pensamiento contemporáneo, sobre este inmanentismo". $Y$ añade: "De haber de decidirlo en una filosofía, parece que había de serlo en una expresa filosofía de sí mismo, en función de una filosofía de Hispanoamérica en general" 48 con lo que Gaos se convierte de algún modo en propulsor de esa filosofía de lo ame-

\footnotetext{
44 Ibid., p. 100.

45 Ibid., pp. 100-101.

46 Ibid., p. 105.

47 Ibid., p. 106.

48 Ibid., p. 111.
} 
ricano, cuyos peligros había anunciado y cuyas exageraciones, en su versión mexicana, habria de exorcizar, como ya vimos.

\section{Valor actual y futuro de la filosofia gaosiana}

He aquí la descripción que Gaos hace del pensador hispanoamericano típico: "El gran conversador que es en tantos casos, y cuáles, el pensador hispanoamericano, se siente satisfecho con la ocurrencia ingeniosa y la frase feliz -hay que decir, pues, estéticamente; personalmente, con la 'vivencia' de la propia fuerza creadora; socialmente, con la impresión producida y percibida en el auditorio limitado y habitual - la tertulia - mucho más que con la eventual en el lector ausente, lejano en el espacio y en el tiempo, desconocido, anónimo, impersonal. Pero en otros casos su conversación sirve a una intención ética y pedagógica; directamente, individual: el moralista y educador expone sus ideas y da sus consejos en la intimidad, al interlocutor único; más indirectamente, social: se cree que el procedimiento formará minorías operantes sobre la nación." 49

Pues bien, esta descripción del pensador hispanoamericano, podría perfectamente pasar por un autorretrato, ya que en él se refleja la actividad e intenciones del pensador de circunstancias que fue José Gaos. La fama que goza de mente profesoral y rigurosa no puede ser suficiente para borrar un hecho evidente de su producción: la preferencia por la expresión de su pensamiento en formas literarias de tipo circunstancial: conferencias, artículos, polémicas, notas críticas sobre libros, encargos editoriales. He repasado la obra escrita de Gaos y no he encontrado ni una sola excepción a lo anterior; cualquiera puede hacer lo mismo repasando los índices y prólogos de sus libros, resultado en su mayoría de la recopilación de diversos trabajos circunstanciales del tipo anterior sobre un tema determinado. No hay en toda su producción un solo libro que haya sido pensado y concebido sin que mediara alguna circunstancia, siquiera sea la del encargo de una editorial. Hasta una obra tan densa y bien trabada como De la filosofia es producto del curso de 1960, último de profesor en activo antes de su jubilación, fruto a su vez de diferentes cursos dados a lo largo de su vida profesoral.

Entre las distintas formas circunstanciales utilizadas por Gaos la que mayor fruición le producia era la clase. $\mathrm{Y}$ así ha dejado constancia de ello en sus Confesiones profesionales: "De $\mathrm{ml}$ he de confesar - escribe- que quizá la única situación de la vida en que estoy prácticamente siempre de buen humor, es la clase. Ya puedo tener preocupaciones, padecer duelos y quebrantos - no físicos, porque en materia de éstos no aguanto nada-; a veces, yendo a dar clase, he ido repitiéndome que no me hallaba en estado

49 Ibid., p. 89 . 
de ánimo para darla; que mejor no la daba, regresaba, avisaba... Entrar en la clase, empezarla -y no acordarme ni de lo que venía repitiéndome, ni de lo que motivara, todo uno." 50 Y hay que tener en cuenta que la actividad pedagógica no la daba Gaos por terminada en la clase, sino que la continuaba en las mil formas que las relaciones personales de amistad pueden tener, preferentemente la reunión y la conversación. En este sentido nos confiesa también: "Personalmente no puedo convencerme de haber hecho menos que con todas mis clases y seminarios, con aquellos paseos de Zaragoza, a la salida de la clase a media tarde, para recalar en una chocolatería del Coso, donde se estaba 'platica' que te 'platica' conmigo media docena de estudiantes, que al anochecer me conducían hasta casa por las añoradas calles relativamente apacibles de la capital provinciana; o con aquellas reuniones ya de aquí, de México, los sábados por la tarde, que espero no hayan olvidado aún del todo algunos de los aquí presentes..." 5 a

Pero no sólo en la relación docente se aprecia el estímulo intelectual que las circunstancias más concretas le producían: la fruición con que Gaos daba conferencias era bien conocida de todos los que le vieron en tal tesitura; el entusiasmo con que reaccionaba a la recepción de un libro nuevo, y que le llevó a redactar numerosas y largas notas críticas; o el mismo entusiasmo con que aceptaba el encargo de una revista o de una editorial para escribir un artículo o un libro, es una prueba más del fecundo estímulo que sobre él ejercían las circunstancias más inmediatas. En este sentido el valor de Gaos no es otro que el valor del ejemplo personal: el de una doctrina filosófica de las circunstancias mantenida y respaldada por una conducta personal, que prueba la fecundidad de la teoría con la práctica.

Pero no termina aquí el valor de esta obra múltiple y riquísima de Gaos. Para Hispanoamérica, no en el sentido gaosiano del término, sino en el restringido de países americanos de habla española, la función de la doctrina de salvación de las circunstancias expuesta por Gaos es doble: por un lado, justifica como quehacer filosófico y de valor original toda una forma de pensamiento hispanoamericano al que se le discutía como tal, considerándolo como meramente literario; por otro lado, la preocupación por las circunstancias nacionales, tanto como continentales, lleva a impulsar los estudios y las investigaciones sobre historia de las ideas en América, asf́ en cada uno de los países en particular, como en el continente en general.

De las tres promociones de discípulos de que habla Gaos en las Confesiones profesiomales - la de los "historiadores", la de los "hiperiones" y la de los "hegelianos"-, los primeros son los que indudablemente gozan de su preferencia. Son los que se han dedicado a la investigación de la historia de las ideas en México; de ellos dice el maestro lo que no dice dé las otras dos

50 Confesiones profesionales, p. 142.

51 Ibid., pp. 93-94. 
promociones: "estoy seguro de que la parte que les corresponde persistirá en la historia de la cultura mexicana en la posición y con la duración de los sillares cimientos de vastos y altos edificios".52

En España, el valor de la doctrina gaosiana es aún mayor, pues junto a las dos funciones que hemos señalado para Hispanoamérica, hay una más: Ia que tiene de justificación para las jóvenes generaciones en el camino emprendido de despegue de un pasado imperial y en la impulsión de un movimiento de independencia espiritual que, a pesar de reunir en torno a los intelectuales más conspicuos, aún no ha triunfado políticamente.

José Gaos es, en este sentido, uno de los más dignos, valiosos y fecundos representantes de la España innovadora, de una España que, gracias a hombres como él, todavía habrá de dar importantes frutos. Esa tradición progresista es la que logra que nuestro pais todavía cuente algo en el mundo y la única que permite una esperanza de futuro para la vida nacional.

Por último, no podemos dejar de mencionar el valor inmenso que la obra, la vida y la doctrina de Gaos tiene para un verdadero y vivo acercamiento entre Hispanoamérica y España, en esa unidad fraterna que -más allá de las consignas y los estereotipos oficiales - realmente existe. Hombres como Gaos son los que garantizan la persistencia y el enriquecimiento de un vínculo auténtico entre lo hispanoamericano y lo español.

José Luis AbelláN 